\title{
Ethnologies
}

\section{Le « complexe » des musées d'ethnographie et d'ethnologie au Québec, 1967 - 2002}

\section{Yves Bergeron}

Volume 24, numéro 2, 2002

Musées

Museums

URI : https://id.erudit.org/iderudit/006639ar

DOI : https://doi.org/10.7202/006639ar

Aller au sommaire du numéro

Éditeur(s)

Association Canadienne d'Ethnologie et de Folklore

ISSN

1481-5974 (imprimé)

1708-0401 (numérique)

Découvrir la revue

Citer cet article

Bergeron, Y. (2002). Le " complexe " des musées d'ethnographie et d'ethnologie au Québec, 1967 - 2002. Ethnologies, 24(2), 47-77.

https://doi.org/10.7202/006639ar
Résumé de l'article

Cet article propose une synthèse du développement des musées d'ethnographie et d'ethnologie au Québec. Le texte met en lumière la contribution originale de l'ethnologie à la muséologie québécoise. Le projet du musée national de la civilisation apparaît en trame de fond et permet de suivre l'évolution des musées d'ethnographie. L'auteur propose une analyse en trois temps pour rendre compte des phases les plus marquantes. En parallèle de cette analyse, on établit les liens entre le développement des musées et la formation en ethnologie et en muséologie. Le texte démontre qu'il existe une corrélation directe entre les formation et la médiation des savoirs dans les musées d'ethnographie. Il existe actuellement une crise du savoir et de la formation en muséologie.
Ce document est protégé par la loi sur le droit d'auteur. L'utilisation des services d’Érudit (y compris la reproduction) est assujettie à sa politique d'utilisation que vous pouvez consulter en ligne.

https://apropos.erudit.org/fr/usagers/politique-dutilisation/ 


\title{
LE « COMPLEXE » DES MUSÉES D’ETHNOGRAPHIE ET D’ETHNOLOGIE AU QUÉBEC, 1967 - 2002
}

\author{
Yves Bergeron \\ Directeur du service de la recherche et de l'évaluation \\ Musée de la civilisation, Québec
}

\begin{abstract}
À première vue, il peut sembler étonnant d'écrire qu'il existe un " complexe » des musées d'ethnographie et d'ethnologie au Québec. Le mot «complexe » renvoie d'abord au concept de réseau des musées. Il fait également référence au sens qu'on lui donne en psychologie, c'est-à-dire un "ensemble de représentations et de souvenirs à forte valeur affective, contradictoires, partiellement ou totalement inconscients, et qui conditionnent en partie le comportement d'un individu. Complexe d'Électre (ou du père); complexe de culpabilité ${ }^{1}$. Comme on le verra dans la présente analyse, le réseau des musées d'ethnographie apparaît complexe à plusieurs égards. Ce titre à double sens permet de faire référence à la fragilité du réseau des musées d'ethnographie et à la crise réelle que ces musées traversent depuis une dizaine d'années. Mais au-delà de cette crise, que l'on peut bien décrire puisqu'elle est observable, il importe surtout de comprendre ce qui explique cette situation.
\end{abstract}

\section{Premières observations de terrain}

Pour aborder le sujet des musées d'ethnographie, j'ai choisi de me placer dans la position de l'ethnologue qui observe. Ma pratique de la muséologie depuis maintenant quinze ans et mon intérêt pour l'évolution du concept du patrimoine ${ }^{2}$, l'histoire des musées (2002) et le phénomène du collectionnement (1996) m'ont permis d'identifier quatre constats majeurs à partir desquels je propose une relecture de l'évolution des musées d'ethnographie au Québec de 1967 à aujourd'hui.

1. Le trésor de la langue française, http://atilf.inalf.fr/tlfv3.htm

2. J'ai coordonné les activités du Groupe-conseil sur la politique du patrimoine 
Premier constat: le programme d'ethnologie offert à l'Université Laval a joué un rôle déterminant dans la formation des muséologues au Québec. Conséquemment, il faut tenir compte du fait que le programme d'ethnologie a influencé considérablement le développement du réseau des musées et de la muséographie originale qui s'est développée au Québec.

Deuxième constat : il existe véritablement une crise des musées d'ethnographie au Québec comme ailleurs dans le monde. Cette crise s'est amorcée il y a une dizaine d'années. Au début des années 1990, on a constaté que les projets concernant les musées d'ethnographie commençaient à susciter de moins en moins d'intérêt. Cette situation peut sembler paradoxale, car la muséologie québécoise connaissait alors une phase de développement sans précédent depuis l'ouverture en 1988 du Musée de la civilisation (voir Grandmont 1991 : 56-59) qui peut être considéré comme un musée d'ethnographie. Cependant, il faut se rappeler que le Musée de la civilisation avait demandé près d'une vingtaine d'années avant de se réaliser. Il s'agit d'un long parcours, débutant en 1967 avec l'ethnologue Jean-Claude Dupont qui propose au ministre de la culture du Québec de créer un Institut national de la civilisation plutôt qu'un Musée de l'Homme du Québec.

Troisième constat : si on acceptait de ne pas se censurer, on pourrait énoncer sans réserve que les musées d'ethnographie sont en quelque sorte en voie de disparition au Québec. S'agit-il d'un problème réel ou d'une simple période de transition ? Est-ce que ce constat préliminaire s'observe également à l'extérieur du Québec ? Je serais naturellement porté à défendre l'idée d'un passage à vide de l'ethnologie dans les musées. On verra notamment de quelle manière l'ethnologie a favorisé le développement des musées tout en contribuant à faire disparaître les musées d'ethnographie.

Quatrième constat: depuis une dizaine d'années, on observe notamment que les muséologues québécois n'osent à peu près plus s'afficher comme «ethnologues » de formation. Comment peut-on expliquer cette situation alors que l'on sait qu'une large partie des muséologues québécois ont fait des études au programme d'ethnologie

sous la présidence de Roland Arpin et j'ai participé à la rédaction du rapport déposé à Agnès Maltais, ministre de la Culture et des Communications du Québec, dans lequel nous traçons un bilan de l'évolution du concept de patrimoine au Québec (voir le chapitre1 dans Arpin et al. 2000 : 1-51). 
du Québec à l'Université Laval ? On pourrait étayer plusieurs hypothèses pour expliquer ce comportement. Dans un premier temps, on pourrait expliquer que l'arrivée d'un programme de maîtrise en muséologie en 1987 a provoqué une rupture avec le mode de formation traditionnelle en muséologie. Alors, comment expliquer que les nouveaux muséologues, formés au programme conjoint de maîtrise de l'Université de Montréal et de l'Université du Québec à Montréal et du diplôme de deuxième cycle en muséologie de l'Université Laval, continuent très souvent à se définir en fonction de leur formation de premier cycle ? Ils n'hésitent pas à dire qu'ils proviennent de l'histoire de l'art, de l'histoire, de l'archéologie, des sciences ou des communications. Seconde hypothèse : il y a de moins en moins de muséologues québécois ayant reçu une formation en ethnologie. Lorsqu'on examine les disciplines d'origine des étudiants de deuxième cycle en muséologie, on constate qu'ils proviennent d'horizons différents et de disciplines diverses. Une troisième hypothèse pourrait être explorée. Ce quatrième constat n'est peut être tout simplement que le résultat des trois constats précédents.

\section{Les musées d'ethnographie et d'ethnologie du Québec en trois temps}

De manière à rendre compte de la situation des musées d'ethnographie et d'ethnologie au Québec, je propose de poser un regard rétrospectif qui permet de mieux comprendre les changements importants observés dans le réseau québécois des musées d'ethnographie. Ce regard rétrospectif débute en 1967, car cette année marque un tournant dans le développement des musées au Québec. Ainsi, j’ai identifié trois périodes marquantes pour les musées d'ethnographie au cours des trente-cinq dernières années. La première période débute en 1967 avec le projet du Musée de l'Homme du Québec et l'analyse qu'en fait Jean-Claude Dupont pour le ministre des Affaires culturelles du Québec. Cette date clé annonce une période de développement du réseau des musées québécois au cours des années 1970. On voit alors apparaître de nouveaux musées régionaux qui s'intéressent tout particulièrement aux identités régionales et qui constituent des collections ethnographiques. La seconde période débute avec le référendum de 1980 et se poursuit jusqu'en 1992 avec le congrès international ICOM des musées qui réunit à Québec ${ }^{3}$ des milliers de

3. Voir à ce propos le numéro spécial de la revue Forces ayant pour thème «Plein feu sur les musées » (été 1992), rassemblant des textes de plusieurs muséologues québécois reconnus. C'était également l'occasion pour ces auteurs de mettre en relief l'originalité de la muséologie québécoise. 
muséologues. Enfin, la dernière période couvre globalement les années 1990 et confirme les tendances observées au cours des années 1980.

Premier temps : l'émergence des musées d'ethnographie, 1967-1980

En 1967, le ministre des Affaires culturelles souhaite doter le Québec d'un musée national d'ethnologie. Le projet initial du gouvernement du Québec s'inspire alors du modèle du Musée de l'Homme à Ottawa. Le rapport de Jean-Claude Dupont, rédigé en 1967 pour le ministre des Affaires culturelles, trace un portrait sans équivoque de la situation des musées au Québec. À cet égard, on peut dire que l'année 1967 constitue une année charnière dans l'histoire de la muséologie au Canada et plus particulièrement au Québec. L'événement historique que constitue l'exposition universelle de 1967 a permis de rassembler à Terre des Hommes une multitude de pays. Montréal devient alors le carrefour des cultures. Cette ouverture au monde que représente l'exposition universelle de Montréal est accompagnée d'une période de changements majeurs dans l'histoire culturelle du Québec. On observe alors un véritable choc des cultures et des différences. Aux yeux des Québécois, le monde et les «autres cultures » ne sont plus simplement des faits divers dans l'actualité, que l'on peut lire dans les journaux ou au mieux que l'on peut entrevoir à la télévision, à une époque où les images nous parviennent encore en différé. Ces «autres cultures » prennent forme et s'expriment à travers une série de pavillons thématiques. Les pays participants font alors appel aux plus récentes technologies de communication. Ce ne sont pas simplement des pavillons qui surgissent sur les îles de Terre des Hommes, ce sont également des musées vivants ${ }^{4}$.

À la suite de cet événement culturel international, le regard des Québécois sur le monde ne sera plus jamais le même. Mais ce qui retient avant tout notre attention, c'est qu'en découvrant les cultures et les patrimoines du monde, on redécouvre ici le patrimoine du Québec. Il ne s'agit certainement pas d'un hasard si la loi québécoise sur les biens culturels élargit quelques années plus tard, au début des années 1970, la notion de patrimoine.

4. Le directeur général du musée de la civilisation, Roland Arpin, a souvent évoqué cet événement historique pour expliquer la philosophie du concept du Musée de la civilisation. Raymond Montpetit reconnaît également l'impact de l'exposition universelle de 1967 (2002 : 81-94). 
La période comprise entre 1972 et 1985 constitue sans aucun doute la période la plus animée pour le patrimoine. La nouvelle Loi sur les biens culturels élargit encore le type d'objets à protéger, en précisant l'archéologie et aussi, désormais, les arrondissements naturels. Les monuments historiques deviennent biens culturels. Plusieurs collections ethnographiques et artistiques font l'objet de classements et de reconnaissances, deux statuts différents que distingue dorénavant la loi (Arpin et al 2000: 29).

Ce n'est donc pas par hasard que le ministre des Affaires culturelles du Québec, Jean-Noël Tremblay, fait l'acquisition en 1968 de la collection Coverdale qu'il confie au nouvel Institut national de la civilisation. On retrouve dans cette collection «quelque 2500 pièces d'origine autochtone, européenne et québécoise ; cette collection est reconnue pour sa qualité, sa représentativité et sa diversité (Dubé 1998 : $33) »^{5}$.

\section{Portrait des musées au Québec ${ }^{6}$ en 1967}

Le mémoire de Jean-Claude Dupont s'ouvre sur une page intitulée «Avertissement». D'entrée de jeu, l'auteur apporte une précision importante: "lorsque j'utiliserai le terme musée d'ethnographie, je veux parler du Musée que nous désignons à tort sous le nom de Musée de l’homme du Québec (le fait de spécifier «du Québec » rectifierait cependant en partie cette erreur)». Dupont donne ensuite quelques définitions de différents types de musées. Cette démonstration lui permet de préciser les distinctions qu'il entrevoit entre le concept de Musée de l'homme et de Musée d'ethnographie. À ses yeux, le Musée de l'homme "montre l'évolution humaine vue à travers le monde dans son entier ; ce n'est pas notre musée » précise-t-il. En contrepartie, il développe davantage son point de vue sur le musée d'ethnographie qui, à ses yeux, «présente de façon détaillée l'évolution naturelle et le peuplement humain d'un pays donné, en montrant comment les ancêtres de ce pays donné ont tiré du sol leur subsistance, comment ils se sont groupés

5. Cette collection sera remise au Musée du Québec au moment du démantèlement de l'INC. La collection Coverdale, tout comme la collection ethnographique, sera finalement confiée au musée de la civilisation en 1984. Nathalie Hamel prépare actuellement une thèse de doctorat en ethnologie à l'Université Laval sur cette collection ethnographique majeure pour l'histoire de la muséologie au Québec.

6. Les paragraphes suivants sont tirés de Arpin et Bergeron dans Pichette 2001 : 408, 410. 
pour se défendre et travailler en commun, etc. C'est le Musée de l'histoire d'un groupe d'hommes; c'est notre musée». Comme on pourra le constater, la question identitaire demeure une préoccupation essentielle dans l'argumentation qu'il développe.

Malgré cette définition assez enthousiaste de ce qu'est un musée d'ethnographie, Dupont démontre que les musées d'ethnographie, tels qu'on peut les voir en 1967, ont peu d'avenir : "Après confrontation de toutes ces données indispensables, il appert que la formule musée d'ethnographie est dépassée, pour ne pas dire morte » (Dupont 1967 : $1)$.

Il peut nous sembler étonnant de lire ces propos venant d'un jeune ethnologue. Dupont recueille d'ailleurs, lors de ses entrevues, des expressions qui définissent le musée d'ethnographie tel qu'on le perçoit à cette époque. Il en donne quelques exemples révélateurs : «Assortiment de curiosités / Sorte d'amusement stérile / Recueil de débris antiques / Passe-temps pour collectionneurs excentriques / Entrepôt de vieux objets poussiéreux confiés à la garde de conservateurs maniaques / Enterrement de première classe, etc. » (1)

Ces commentaires recueillis lors d'entrevues dans le réseau des musées québécois lui suggèrent donc la conviction qu'il «faut trouver une formule nouvelle pour intéresser le peuple à l'étude de la civilisation ». Il semble clair, dans l'esprit de Dupont, que la vision de la muséologie ne se trouve plus en adéquation avec la société québécoise de la fin des années 1960. Ses nombreuses entrevues lui permettent d'ailleurs de conclure que le musée, "pour le peuple, c'est encore le séjour des muses de l'Antiquité » (1).

Dans son rapport, Dupont exprime un point de vue critique sur les différentes fonctions des musées. Il précise que le Musée, contrairement à ce qu'on dit souvent, n'a pas été conçu pour la recherche. Il suggère plutôt que le musée, historiquement, est plutôt apparu comme une solution « de débarras pour les collectionneurs qui avaient des richesses personnelles, livres, peintures, objets d'art, bijoux, armes, etc.» (2). Il ajoute d'ailleurs, à titre d'exemple, qu'au « début du XXe siècle, le Musée national du Canada se donne pour fonction d'être l'entrepôt naturel de tous les objets de valeur scientifique du Canada (voir charte)» (2).

À la lecture du rapport de Dupont, une question se pose : peut-on vraiment parler de musées d'ethnographie en 1967 ? Lorsqu'on prend 
connaissance du réseau des musées au Québec à cette époque, on constate rapidement que les musées privés ressemblent plutôt à des cabinets de curiosités. Même s'ils conservent des collections ethnographiques, ces musées ne disposent pas de programme scientifique ni de programme de documentation des collections. En ce sens, on peut constater qu'il n'existe pas, à la fin des années 1960, de véritable musée d'ethnographie au Québec. Tout au plus, on retrouve des musées d'histoire qui accumulent dans leurs réserves des objets témoins de la vie quotidienne et de la culture populaire. Le seul modèle que les muséologues québécois connaissent demeure le Musée de l'Homme à Ottawa.

Il faut rappeler que le Musée de l'Homme s'inscrit dans une longue histoire qui plonge ses racines historiques au Québec. Dès la création de la Commission géologique du Canada en 1842, les géologues prospectent et analysent les ressources naturelles du Canada-Uni (Vodden 1992). Ils parcourent alors le territoire du Québec et de l'Ontario et ils constituent des collections minéralogiques et géologiques qu'ils exposent dans un musée aménagé dans l'édifice de la Commission géologique situé sur la rue Saint Gabriel à Montréal (1852-1881). La Commission géologique offre également des collections à des musées et à des institutions d'enseignement. C'est ainsi que l'Université McGill, le Séminaire de Québec et plus tard l'Université Laval reçoivent des collections constituées par les premiers géologues canadiens (Bergeron $2002: 51-72$ ).

Alors qu'ils explorent le territoire canadien, les géologues collectent des objets ethnographiques appartenant à des communautés amérindiennes et inuit. C'est ainsi qu'on a commencé à constituer la première collection ethnographique au pays. Ces collections scientifiques et ethnographiques de la Commission géologique du Canada sont à l'origine du premier Musée de l'Homme au Canada. C'est dans ce contexte que l'anthropologue Marius Barbeau entre au Musée national du Canada en 1910.

Bien qu'il n'existe pas de véritable musée d'ethnographie au Québec, le Musée de l'Homme du Canada demeure le modèle de référence au pays. Il n'est donc pas étonnant que le ministre des Affaires culturelles du Québec souhaite créer en 1967 un Musée de l'Homme du Québec. 


\section{Musées d'art et musées d'ethnographie}

On peut supposer que Dupont mesure le fossé qui existe à la fin des années 1960 entre les musées d'art et les musées d'ethnographie. Gérard Morisset avait déjà établi des bases solides pour l'histoire de l'art du Québec (1981 ; voir aussi Garneau 1979). Les conservateurs des beauxarts disposent alors d'une meilleure formation. Conséquemment, les collections d'arts québécois se trouvent mieux documentées. Quant aux collections ethnographiques, elles demeurent encore dans le cercle restreint des collectionneurs et des amateurs d'antiquités. À toute fin pratique, on ne trouve pas d'ethnologues de la culture matérielle dans les musées québécois. Les travaux d'ethnologues en culture matérielle restent rares. Barbeau a publié quelques ouvrages sur les artisans (1937; 1957 ; voir aussi Béland 1985). Par ailleurs, Robert-Lionel Séguin commence à publier des articles et des ouvrages sur la culture matérielle québécoise ${ }^{7}$. Mais en somme, tout reste à faire. Cette analyse de la situation des musées conduit Dupont à constater qu'il y a un travail énorme à réaliser dans le champ de la culture matérielle ${ }^{8}$. En fait, il semble que Dupont ne fasse pas clairement la distinction entre musée d'histoire et musée d'ethnographie. Ce qu'il présente comme des musées d'ethnographie, ce sont essentiellement des musées régionaux qui se consacrent à l'histoire et qui conservent cependant des collections ethnographiques.

En ce qui concerne la muséographie des musées, il souligne l'étalage statique et permanent qui, dit-il, fatigue les visiteurs. Ses propos à ce sujet sont assez sévères :

Un élément qui concourt à la faillite des musées d'ethnographie c'est la notion de musée entrepôt où les spécimens en permanence fatiguent les visiteurs. C'est l'éternité et la banalité des expositions en permanence (Dupont dans Pichette $2001: 3$ ).

En somme, il existe à la fin des années 1960 de nombreux musées d'histoire qui possèdent des collections ethnographiques, mais qui ne

7. Lorsqu'on songe à Robert-Lionel Séguin, on pense notamment à son ouvrage majeur publié en 1967, La civilisation traditionnelle de l' "habitant » aux $17^{e}$ et $18^{e}$ siècles. Voir également la bibliographie exhaustive de Séguin dans Bouchard (1983).

8. À cet égard, Dupont assumera ses responsabilités puisqu'il consacre sa carrière à l'étude de la culture matérielle (voir sa bibliographie dans Pichette 2001 : 473-486). 
disposent pas encore du professionnel apte à étudier et à mettre en valeur ces collections ethnographiques. L'Université Laval forme des étudiants en ethnographie depuis 1944, mais ceux-ci se spécialisent plutôt dans la perspective du folklore et des traditions orales. Il existe alors un déficit majeur pour la formation scientifique en culture matérielle9.

Pour des raisons personnelles, Dupont quitte l'Institut national de la civilisation dont il a défini les objectifs ${ }^{10}$ dans son rapport déposé en 1967. L'année suivante, il intègre l'équipe de Luc Lacourcière en Études canadiennes. Dès la session d'automne, Dupont donne un premier cours correspondant à son projet de thèse consacré à "L'artisan forgeron ${ }^{11}$ ». Rapidement, il prépare de nouveaux cours généraux sur la culture matérielle. On entre, au début des années 1970, dans une période d'effervescence. Le programme de folklore s'ouvre alors au secteur de la culture matérielle. Ce nouveau champ de recherche permet l'émergence de nombreux travaux sur les objets et les métiers traditionnels. Les ethnologues québécois investissent un champ qui était demeuré à toute fin pratique vierge. Les années 1970 marquent un tournant majeur pour les travaux de recherche en culture matérielle. Jean Simard, qui faisait également partie de l'Institut national de la civilisation, rejoint bientôt le programme d'ethnologie. Il apporte une dimension nouvelle à la culture matérielle et contribue notamment à donner un souffle nouveau aux travaux de recherche. Parallèlement à cette nouvelle orientation du programme d'ethnologie, on constate que le nombre d'inscriptions au programme ne cesse de progresser. De nombreux jeunes étudiants sont séduits par la perspective de l'ethnologie qui offre à la fois un regard anthropologique sur la culture populaire et un regard neuf sur la culture matérielle.

9. Jean du Berger décrit le contenu du certificat en folklore offert au département d'études canadiennes. Les cours sont consacrés à l'étude des contes, des légendes, des chansons, des traditions populaires ainsi qu'à des enquêtes folkloriques (voir du Berger 1997 : 17).

10. Ces objectifs sont confirmés dans l'entrevue accordée par le directeur de l'INC, Pierre Lachapelle, publiée dans Culture vivante (1969: 3).

11. La thèse de Dupont, L'artisan forgeron (1979), demeure encore aujourd'hui exemplaire à plusieurs égards. Elle repose avant tout sur les enquêtes orales, mais intègre les dimensions historiques et sociales. Dupont tient compte à la fois de la tradition du geste et de la parole. 
Avec un certain recul, les années 1970 apparaissent aujourd'hui comme l'âge d'or de l'ethnologie québécoise à l'Université Laval, que l'on désigne alors comme le programme d'arts et traditions populaires (Dupont 1997 : 25-48; Moussette 1982 : 7-42).

De cette première vague d'étudiants, plusieurs jeunes ethnologues se retrouvent bientôt dans des musées comme chercheurs, conservateurs et directeurs. Plusieurs ethnologues intègrent l'équipe nationale de Parcs Canada à Ottawa alors que se prépare la vaste opération de régionalisation du réseau des lieux historiques. En 1975, on voit apparaître à Québec le bureau régional de Parcs Canada qui a la responsabilité de mettre en valeur les lieux historiques et les collections ethnographiques sur l'ensemble du territoire québécois. Ces ethnologues occupent des postes au service des collections et au service des expositions, dans les équipes d'archéologie et dans les ateliers de restauration. La formation qu'ils ont acquise en ethnologie et, plus particulièrement, en culture matérielle les prépare bien à travailler avec des collections ethnographiques dans des perspectives d'interprétation et de mise en valeur.

Dans un article publié par l'Institut québécois de recherche sur la culture, Paul-Louis Martin analyse la production des travaux en ethnographie de 1970 à 1980. Il débute son texte en précisant que l'ethnographie est alors devenue une discipline pleine et entière qui contribue à la connaissance de l'histoire :

L'ethnographie, source de l'histoire : nul ne peut plus défendre le contraire. Comprendre les manières de vivre et de produire des groupes humains, connaître leurs systèmes culturels, leurs technologies, leurs structures sociales précède obligatoirement l'interprétation de leur passé, fournie non plus par la seule séquence événementielle mais aussi par l'explication riche et dense de la vie (Martin 1983 : 149).

Martin démontre l'originalité des travaux menés en ethnographie et notamment dans le secteur de la culture matérielle. Il décrit cette effervescence comme

un boom de l'ethnographie ou du patrimoine matériel, ou de l'histoire concrète, comme il plaira de l'appeler, [qui] a constitué ces quinze dernières années un développement sans précédent pour les sciences historiques, l'équivalent - toutes proportions gardées - d'une baie James pour le génie technique. Dans ces conditions et dans le contexte d'une administration publique avant tout fonctionnelle, des écarts 
étaient et sont encore inévitables. Par ailleurs, les conditions de l'amélioration sensible des approches et des travaux ethnographiques se précisent davantage depuis la création du centre de recherche qu'est le CÉLAT. Les disciplines commencent à s'ouvrir davantage les unes aux autres, les recherches s'inscrivent et s'intègrent dans un cadre global de la connaissance et finalement plusieurs programmes de travaux aux objectifs clairs ont été mis sur pied depuis trois ou quatre ans (166).

On ne saurait évoquer cet essor majeur des travaux en culture matérielle sans mentionner le cas particulier de l'historien de l'art et ethnologue de l'Université du Québec à Montréal, Michel Lessard. En 1971, Michel Lessard publie l'Encyclopédie des antiquités du Québec. Cet ouvrage, destiné au grand public, va connaître un succès exceptionnel. Réédité à plusieurs reprises, il devient la référence des amateurs d'objets anciens. Un an plus tard, Lessard publie cette fois l'Encyclopédie de la maison québécoise. Écrit dans le même esprit que le précédent, cet ouvrage connaît également une très large diffusion. Par ailleurs, Lessard s'associe à des cinéastes et produit pour la télévision des séries consacrées au patrimoine québécois. Pour bien comprendre ce contexte d'effervescence des années 1970, on doit tenir compte de la contribution de chercheurs comme Lessard qui s'adressent au grand public ${ }^{12}$.

Parallèlement à cet essor exceptionnel en culture matérielle, les années 1970 marquent également une nouvelle phase de développement pour le réseau des musées québécois. Le rapport du ministre des Affaires culturelles, Jean-Paul Lallier, publié en 1976, annonce des changements importants. On propose de créer une Régie du patrimoine, une direction des musées et de mettre en place un réseau cohérent de musées, de centres d'exposition et de centres d'interprétation. En somme, le gouvernement fédéral et le gouvernement provincial investissent massivement dans des infrastructures de mise en valeur du patrimoine.

12. Michel Lessard se lance au milieu des années 1990 dans la rédaction d'une mise à jour de son Encyclopédie des antiquités. Il publie cette fois trois ouvrages qui, une fois de plus, connaissent un succès inégalé auprès du grand public : Objets anciens du Québec. La vie domestique (1994), Antiquités du Québec (1995) et Meubles anciens du Québec (1999). 
La contribution du Musée des arts et traditions populaires à Paris

En France, on doit tenir compte de l'impact du nouveau musée des arts et traditions populaires à Paris. Le ministère de la Culture et des Communications inaugure en 1972 la galerie d'étude et, en 1975, la galerie culturelle du Musée national des arts et traditions populaires. Ce musée, œuvre de Georges-Henri Rivière et de Jacques Pasquet, représente le meilleur exemple de ce qu'est à l'époque un musée d'ethnographie. L'originalité de ce musée réside notamment dans la cohabitation avec le Laboratoire d'ethnologie française. Pour chaque projet, les muséologues travaillent avec des chercheurs et des scientifiques. Les concepteurs du musée et de la galerie culturelle associent d'ailleurs à leur démarche Claude Lévi-Strauss. Avec quelques années de recul, Jean Cuisenier fait le point sur la situation de l'ethnographie en regard des autres disciplines au milieu des années 1970.

En trente ans aussi, le champ intellectuel a profondément changé. L'anthropologie sociale et ses sources universitaires anglo-saxonnes ont acquis droit de cité grâce aux enseignements de Claude LéviStrauss au Collège de France. On ne pouvait pas ne pas se demander dans quelle mesure les démarches méthodiques, les hypothèses théoriques et le genre de résultats que suscitait la nouvelle discipline pouvaient s'appliquer aux sociétés européennes et singulièrement à la France. Les historiens manifestaient, de leur côté, un intérêt de plus en plus soutenu pour les interrogations des ethnologues et des sociologues, pour leur manière de traiter les données sociales, pour leurs propositions de réinterprétation du passé. Les investigations archéologiques, longtemps orientées par le souci de remonter jusqu'aux périodes les plus lointaines de la préhistoire, commençaient à s'appliquer au Moyen Âge, à la Renaissance et aux Temps modernes. La sociologie, enfin, était en pleine mutation, stimulée par les changements de la société industrielle, les conflits sociaux et les effets multiples de la croissance économique. Il en advenait de même pour une discipline restée longtemps en marge, la folkloristique : cantonnée jusqu'alors dans l'étude des traditions orales et le recueil des coutumes, elle était en plein renouvellement théorique sous l'effet conjoint du structuralisme, de la psychanalyse et de la sémiotique (Cuisenier 1987 : 221).

Le rayonnement du Musée des ATP s'étend alors sur l'ensemble de la France et bien au-delà des frontières. L'enseignement de la muséologie de Georges-Henri Rivière devient la référence de la nouvelle muséologie. Encore aujourd'hui, sa vision de l'ethnomuséologie demeure 
originale et actuelle. Pour bien comprendre la muséologie québécoise, il importe de replonger dans les textes de Georges-Henri Rivière (Cours de muséologie 1980) qui ont inspiré les muséologues d'ici et d'ailleurs.

\section{La question de la formation professionnelle en muséologie}

Les investissements que s'apprêtent à réaliser les gouvernements nécessitent par ailleurs une main d'œuvre qualifiée. Or, il n'existe aucune formation en muséologie au Québec. Certains choisissent alors de poursuivre des études de deuxième cycle en muséologie au Canada et à l'étranger. Plusieurs choisissent de poursuivre leur formation en s'engageant dans des études de deuxième et de troisième cycle au programme d'ethnologie de l'Université Laval. Lorsque l'on examine attentivement les sujets des mémoires et des thèses, on constate que plusieurs concernent la culture matérielle et qu'ils gravitent dans le secteur de la muséologie et de la mise en valeur du patrimoine. Dans les faits, le programme d'ethnologie a longtemps assumé un rôle de formation en muséologie. Le programme accueillait à la fois les étudiants qui voulaient acquérir des habiletés en muséologie et en archéologie historique. C'est par le biais du programme que des chercheurs comme Marcel Moussette, qui dirige l'équipe de chercheurs en culture matérielle de Parcs Canada à Québec, vont soutenir des thèses originales sur la culture matérielle (Moussette 1983).

Cette incursion de l'ethnologie sous l'angle de la culture matérielle fait en sorte que la discipline se retrouve au cœur de ce nouveau champ qu'est le patrimoine. Dès lors, le patrimoine ne concerne plus essentiellement l'histoire de l'architecture et des œuvres d'art. Par le rayonnement qu'il connaît, le programme d'ethnologie incite les gouvernements à élargir le concept de patrimoine pour y intégrer l'étude de la culture populaire. C'est dans cette perspective que le ministère des Affaires culturelles entreprend, par exemple, des inventaires thématiques comme celui consacré aux croix de chemins et l'ambitieux projet de macro-inventaire du patrimoine québécois.

C'est dans ce contexte qu'en 1977 la Direction générale du patrimoine entreprit le programme de macro-inventaire, qui visait à réunir, dans les délais aussi courts que possible, un minimum acceptable de connaissances pour tout le Québec et ce, sur l'ensemble des thèmes et des phénomènes associés au patrimoine. Le macro-inventaire a été conçu comme un outil permettant de dégager une vue d'ensemble de la richesse patrimoniale du Québec et de relever les concentrations 
ou les thèmes susceptibles de faire l'objet d'une recherche ultérieure. Par le fait même, il constitue un excellent instrument de planification (Macro-inventaire du patrimoine québécois 1985 : 9).

Ces travaux menés sur le terrain par des ethnologues insufflent également un élan sans précédent au niveau des dossiers de classement déposés à la Commission des biens culturels du Québec (Les chemins de la mémoire 1990-1999 tome 1). Lorsqu'on analyse avec attention les types de classements faits par la Commission des biens culturels, il apparaît assez clairement que les biens culturels classés ou reconnus ne sont plus de même nature. On ne classe plus uniquement des églises, des presbytères ou des maisons de pierre construite sous le régime français. On voit apparaître d'humbles maisons de bois, des écoles de rang, des documents d'archives et des biens historiques mobiliers ${ }^{13}$. En somme, les préoccupations des ethnologues pour la culture populaire transforment la vision élitiste du patrimoine que les gouvernements entretenaient depuis la création de la Commission des lieux et monuments historiques du Canada en 1991 et l'adoption par le gouvernement québécois de la Loi sur les monuments historiques et artistiques en 1922. En ce sens, l'ethnologie contribue à un mouvement de démocratisation de la culture. Il s'agit certainement d'une contribution originale de l'ethnologie à la société québécoise.

\section{Deuxième temps : 1980-1992}

\section{0 : I'année de toutes les désillusions}

Il faut reconnaître que la politique ou, du moins, les intérêts politiques ont toujours influencé le développement culturel. Le référendum de 1980 constitue certainement le meilleur exemple du genre. L'intérêt pour la culture populaire, pour les objets anciens et le patrimoine de façon générale va, à toute fin pratique, disparaître. En l'espace de quelques mois, la déprime qui suit le référendum est bientôt doublée d'une crise économique majeure. Le gouvernement québécois, qui s'était engagé dans des opérations de développement au cours des années 1970, doit maintenant composer avec une crise économique qui frappe notamment la culture. Le ministère des Affaires culturelles

13. Voir les tableaux 7 et 8 dans Arpin et al. $(2000: 56,57)$. Pour mieux comprendre les changements apportés à la loi sur les biens culturels, on peut consulter Dumouchel (1987) ainsi que le tableau 2 dans Arpin et al. (2000: 28). 
abandonne de nombreux projets et doit éliminer plusieurs programmes de financement. Le secteur des musées et du patrimoine va s'engager dans une longue traversée du désert. Le ministère abandonne bientôt la direction du patrimoine de même que la direction des musées. Dans le même esprit, le ministère modifie la loi sur les biens culturels de manière à ne plus supporter à lui seul les responsabilités liées au classement des biens culturels. On propose de confier aux municipalités la responsabilité de désigner et de protéger le patrimoine. Ces choix se doublent d'une nouvelle tendance qui pousse le gouvernement à régionaliser les ministères. Cette opération aura pour effet de démanteler les équipes nationales et de faire disparaître l'expertise acquise au ministère des Affaires culturelles en muséologie et en patrimoine. Ce constat a d'ailleurs été noté dans le rapport Arpin sur la politique du patrimoine culturel (2000: 41).

\section{L'entrée en scène du Musée de la civilisation}

On ne saurait expliquer le développement du réseau des musées sans évoquer la saga du Musée de la civilisation. Bien que le projet d'un musée national de la civilisation remonte à 1967, il faut attendre le conflit suscité par le projet du Musée de l'Homme d'ici pour que le Musée de la civilisation voie véritablement le jour.

En 1979, Denis Vaugeois dépose un document qui va laisser de nombreuses traces: Le Musée du Québec en devenir (1979a; voir également 1979b). Le rapport démontre que le Musée du Québec, depuis son inauguration en 1933, ne s'est jamais « vu assigner un rôle précis par les autorités gouvernementales, si bien qu'il connut diverses orientations, au gré des directeurs, chacun privilégiant tel ou tel aspect de la culture québécoise et telle ou telle utilisation des ressources disponibles»(1979a: 15). Le ministre des Affaires culturelles du Québec souhaite alors élargir la vocation du Musée du Québec. En somme, le ministère espère conserver le volet beaux-arts et y ajouter un nouveau volet ethnologique :

En choisissant pour objet de son action l'homme d'ici, étudié dans une perspective à la fois culturelle et sociologique, le Musée du Québec s'engage carrément dans le champ d'intérêt des sciences humaines. Il écarte, du même coup, les sciences naturelles et la technologie. Et, bien qu'il se propose de mettre en valeur une importante collection d'art, le Musée du Québec cherchera, en ce 
domaine, à montrer comment l'art fait partie de la vie de notre communauté et s'y intègre sans heurt ni hiatus.

De ce qui vient d'être dit, on comprendra que le Musée du Québec s'inscrira plutôt dans la lignée des musées de l'Homme, lesquels visent, en général, à regrouper la somme des connaissances acquises sur l'espèce humaine. Bien peu de musées de l'homme ne dévient point, cependant, de l'homme universel vers l'homme national, objet plus pro-privilégiant des perspectives assez semblables à celles qu'on retrouve dans les musées de l'homme, le Musée du Québec se distinguera néanmoins de ces derniers par son option volontaire et clairement avouée en faveur de l'homme québécois » (29-30).

Cette proposition, suivie d'une consultation publique, suscite les plus vives réactions dans le milieu des musées au Québec. En somme, ce projet est reçu négativement et vécu comme un drame. Comment pouvait-on envisager en 1979 de faire du Musée du Québec un musée national ouvert à des questions de société ? On assiste alors à une polarisation des positions. Des barricades s'érigèrent entre le milieu des beaux-arts et les muséologues du ministère des Affaires culturelles.

Il faut retourner dans les journaux de l'époque pour constater à quel point le débat prend des proportions démesurées. D'un côté comme de l'autre, les partisans adoptent une attitude qui les place dans une situation de dialogue de sourds. Certains historiens de la muséologie ne retiennent de cette période que la confrontation. Mais il y a beaucoup plus important à retenir. Le projet du ministère des Affaires culturelles devient le prétexte pour amorcer un véritable débat sur la fonction des musées dans la société.

Quoi qu'il en soit, après quelques mois d'un débat qui ressemble plutôt à une querelle de disciplines, le gouvernement ne peut que battre en retraite. Le Musée du Québec est alors confirmé dans sa mission de conservation et de diffusion de l'art au Québec. Quant au second volet consacré à l'homme d'ici, le ministère choisit plutôt de réfléchir à nouveau à ce concept et de préparer la création d'un musée national de la civilisation. Il y a dans cette décision toute politique la préfiguration d'une tendance qui ne s'est pas démentie depuis. En fait, cette polarisation des positions ouvre la porte à une spécialisation des musées. La conséquence la plus immédiate se manifeste dans la mission du Musée du Québec, qui délaisse une partie importante de sa responsabilité initiale qui était de conserver non seulement les œuvres mais également les objets propres à retracer l'histoire du Québec. 
Dès lors, la collection ethnographique constituée par le Musée du Québec est donc confiée au ministère des Affaires culturelles. Quelques années plus tard, le ministère crée le Musée de la civilisation dans un projet de loi adopté par l'Assemblée nationale en 1984. La collection ethnographique qui s'est constituée dès l'ouverture du Musée du Québec en 1933 est confiée cette fois au Musée de la civilisation.

Avec le recul du temps, on constate que ce qui s'annonçait comme un échec en 1979 se transforme en succès. Même avec son concept muséologique propre, on doit reconnaître que le volet " civilisation » n'aurait jamais trouvé un véritable épanouissement dans la structure du Musée du Québec. La création de deux structures autonomes permet donc le maintien et le développement des missions respectives du Musée du Québec et du Musée de la civilisation.

Les difficultés rencontrées par les artisans du Musée de la civilisation vont cependant se transformer et donner naissance à une institution originale qui va devenir le modèle de la nouvelle muséologie.

\section{Les facteurs qui ont contribué au succès}

Il faut bien l'avouer, une large part du succès du Musée de la civilisation réside précisément dans la rupture avec l'approche traditionnelle des musées d'ethnographie. Contrairement à la pratique courante, le Musée ne fait pas des collections le cœur de ses opérations et de sa réflexion. Roland Arpin propose plutôt de centrer le Musée sur l'aventure humaine et de structurer la programmation des expositions, des programmes éducatifs et des activités culturelles autour de thématiques (Arpin 1993). Les objets sont présents, mais ils servent avant tout à supporter le discours des expositions. Cette approche, il faut bien l'avouer, a soulevé bien des controverses. En adoptant une nouvelle façon de concevoir la muséologie, Roland Arpin propose une forme de disruption ${ }^{14}$ de la muséologie. De plus, il remet en question le rôle des conservateurs en confiant la réalisation des expositions à des chargés de projets qu'il imagine être des spécialistes de la communication. Cette approche pédagogique s'inscrit également en contradiction avec le modèle traditionnel. Cette seconde disruption a secoué le milieu des musées car il remet alors en question les valeurs les plus fondamentales des muséologues.

14. À propos du concept de disruption, on peut consulter Dru (1997). 
Le concept muséologique du musée de la civilisation propose une troisième rupture fondamentale. De manière à échapper au piège des disciplines, les auteurs du concept ont choisi de créer un musée multidisciplinaire. Le Musée de la civilisation ne se veut pas un musée d'ethnographie, ni un musée d'histoire, ni un musée d'anthropologie. Il se définit comme un musée de société. C'est pourquoi chaque projet d'exposition fait appel à des chercheurs qui proviennent de toutes les disciplines, de manière à ce que les thèmes ne soient pas traités en regard d'un seul point de vue disciplinaire (Bergeron 2002 : 173-213). Par cette prise de position, le Musée de la civilisation préfigure une nouvelle tendance fondamentale. En somme, le musée annonce la remise en question des musées disciplinaires.

Lorsqu'on examine objectivement ces choix stratégiques, on constate que les musées d'anthropologie ou d'ethnologie comme les musées d'histoire ne peuvent plus se permettre de s'enfermer dans des perspectives uniques. Cependant, l'approche muséologique centrée sur l'aventure humaine ne s'inscrit pas en contradiction avec l'approche ethnologique, bien au contraire. Cette approche s'apparente plutôt à la démarche ethnologique dans la mesure où elle permet de centrer le discours muséologique du point de vue des personnes en tenant compte de la culture populaire. Faut-il rappeler que l'équipe initiale du Musée de la civilisation comptait un nombre important d'ethnologues qui occupaient des postes clés (conservateurs, chargés de projets, chargés de recherche et directeurs). L'analyse des scénarios des premières expositions révèlerait certainement une préoccupation particulière pour la culture populaire. On n'a qu'à penser aux premières expositions produites au Musée de la civilisation comme Mémoires ${ }^{15}$ qui a marqué la muséologie nord-américaine ou comme Souffrir pour être belle ou Cher amour (Arpin 1988-2001 : 32-52). Dans cette perspective, le Musée n'est plus le lieu d'expression des élites et le porte parole de leurs valeurs. En centrant l'exposition sur l'aventure et l'expérience humaine, on

15. L'exposition permanente Mémoires, qui présente l'identité et l'histoire des Québécois, demeure encore aujourd'hui le meilleur exemple de l'approche originale développée au Musée de la civilisation. Cette exposition repose d'abord et avant tout sur les travaux d'une équipe multidisciplinaire du CÉLAT à l'Université Laval. Philippe Dubé, aujourd'hui responsable du diplôme de deuxième cycle en muséologie, en était le chargé de projet. Bien qu'elle doive être remplacée en 2005, elle reste une des expositions les plus appréciée du grand public. 
oblige les muséologues à sortir du culte des objets. En s'engageant sur cette voie, le Musée de la civilisation renouvelle le regard sur la société et, en ce sens, il apporte une nouvelle vision de ce que peut être un musée de société. Même si le Musée se définit comme un musée de société et rejette toute étiquette qui pourrait le lier à une discipline, il demeure fondamentalement un musée ethnographique. En ce sens, on peut dire que le Musée de la civilisation apparaît comme l'aboutissement de ce projet de Musée de l'Homme évoqué dès 1967.

\section{La question de la formation professionnelle en muséologie}

L'apparition du Musée de la civilisation et le développement du réseau des musées suscite de nouvelles préoccupations au plan de la formation professionnelle. C'est dans ce contexte que le ministère de la main-d'œuvre et de la sécurité du revenu entreprend une consultation de manière à proposer un devis de formation professionnelle pour les conservateurs de musée. Ce devis a pour objectifs de donner aux membres du domaine muséal toutes les dimensions de la profession de « conservateur-conservatrice », de définir les aires de compétence reconnues, de fournir aux institutions muséales une description détaillée des tâches, qualités et compétences. De plus, cette opération vise à permettre l'élaboration de programmes de formation professionnelle et de perfectionnement. Ce rapport rappelle que la Société des musées québécois demeure le seul organisme qui forme officiellement les professionnels de la muséologie. On définit ainsi la problématique :

Les musées se développent et se professionnalisent à un rythme accéléré depuis 1970. Le personnel en place doit s'adapter pour faire face aux problèmes pratiques qu'il rencontre dans l'accomplissement de ses tâches: outils de recherche sur les collections, techniques de conservation et de restauration, implantation de l'information, méthodes et techniques de présentation des expositions, élaboration de guides pédagogiques, nouvelles techniques de communication, de mise en marché, et de gestion (Ministère de la main d'oeuvre et de la sécurité du revenu 1987).

Les auteurs du rapport reconnaissent que le travail de conservateur exige une formation de deuxième ou de troisième cycle dans six disciplines reconnues: histoire, histoire de l'art, ethnologie, anthropologie, archéologie, sciences et technologies. On précise que pour devenir conservateur, les candidats doivent avoir une connaissance de la muséologie par le biais de formations spéciales ou par l'expérience 
acquise dans un musée. Ce rapport arrive au moment où l'Université de Montréal, l'Université du Québec à Montréal et l'Université Laval proposent un programme de maîtrise en muséologie. Disposant d'une solide expérience en ethnomuséologie et d'une longue tradition, l'Université Laval sera finalement écartée dans la mesure où l'Université de Montréal et LUQAM proposent un programme conjoint de maîtrise en muséologie. L'Université Laval doit abandonner le programme de maîtrise, mais propose un diplôme de deuxième cycle en muséologie avec le support du programme d'ethnologie.

Au-delà de cette bataille qui oppose trois universités, on doit constater que les musées jouissent d'une notoriété indéniable. C'est dans ce contexte de développement et de valorisation du rôle du musée dans la société que la formation des muséologues se professionnalise.

\section{Troisième temps : la fin des musées d'ethnographie ?}

Dans le sillage du succès international que connaît le Musée de la civilisation, le réseau des institutions muséales se développe largement (Ministère de la culture et des communications 2000 : 9-12). Les politiciens et les décideurs envisagent alors de faire des musées des moteurs du développement culturel et économique. De nombreux projets émergent tout à coup. Plusieurs musées proposent des plans de relance et de développement; c'est le cas du musée du Séminaire de Sherbrooke, du musée de Joliette, du musée McCord et du Musée du Séminaire de Québec qui souhaite se transformer en musée de l'Amérique française ${ }^{16}$. Et puis, de nouveaux projets se concrétisent. Le gouvernement fédéral propose de construire à Québec un musée de la Nouvelle-France; le gouvernement québécois annonce l'agrandissement du Musée du Québec et la construction d'un Musée des Arts et traditions populaires du Québec à Trois-Rivières.

Cette euphorie qui gagne le réseau des musées connaît son apogée avec le congrès international des musées qui se tient à Québec à l'automne 1992. Le réseau des musées québécois et canadiens acquiert alors une reconnaissance internationale.

16. Voir à ce propos la publication de la Commission des biens culturels pour le colloque ICOM (Simard 1992). 
Jamais, sans doute, on n'aura parlé de musées au Québec qu'en cette année 1992 qui a vu en mai, à Montréal, la réouverture du musée McCord dans des locaux restaurés et agrandis, l'installation du Musée d'art contemporain dans un bâtiment neuf intégré à la Place des arts, et qui verra en septembre, à Québec, les assises de la XVI ${ }^{\mathrm{e}}$ Conférence générale du Conseil international des musées (ICOM), regroupant quelque 9000 membres partout dans le monde.

L'année 1992, qui est à plusieurs égards celle des grands anniversaires au Québec, peut aussi être considérée comme l'année des musées et de la muséologie, car jamais on n'a vu s'affirmer une telle vitalité dans ce secteur» (Couture 1992: 4-10).

La crise économique qui se profile au début des années 1990 va cependant ralentir considérablement les projets de développement des musées. Le gouvernement québécois préfère s'engager dans des investissements culturels pour des projets de centres d'exposition et de centres d'interprétation. Cette tendance (Simard 1992), qui se confirme dans la décennie 1990, est déjà perceptible au milieu des années 1980. Les politiciens comprennent rapidement qu'il est plus simple de construire des centres d'interprétation pour développer le tourisme régional. Ces centres demandent un investissement important en immobilier, mais ils nécessitent peu de ressources financières au plan du fonctionnement. En d'autres termes, pour une fraction du coût d'un musée conventionnel, l'état peut créer plusieurs centres d'interprétation. De plus, aux yeux des citoyens, il n'existe pas de différence entre musée et centre d'interprétation. Dès lors, les centres d'interprétation s'inscrivent dans les agendas politiques des ministres et des députés.

Par ailleurs, à compter de 1991, le gouvernement du Québec et le gouvernement fédéral investissent massivement dans l'informatisation des collections publiques (Arpin 2000 : 62). Cette politique favorise le travail de recherche sur les collections ethnographiques des musées canadiens.

Cette nouvelle orientation provoque des impacts majeurs. Le premier et le plus significatif : on abandonne la création de musées ethnographiques dans les régions. On préfère traiter des identités régionales dans des expositions permanentes qui prennent la forme de centres d'interprétation. Des firmes se spécialisent et créent des centres d'interprétation dans les différentes régions du Québec. Première conséquence, ces centres d'interprétation n'ont pas besoin de conservateurs ou d'ethnologues en permanence. Ce type d'institution 
muséale ne se définit pas comme un lieu de connaissance et d e conservation de la mémoire populaire. Les centres d'interprétation deveinnent des lieux de promotion de certaines thématiques. Deuxième conséquence : on crée un réseau de musées statiques, c'est-à-dire qu'on y fige des thématiques qui n'évoluent à peu près pas et qui ont pour conséquence de ne pas fidéliser les clientèles locales et régionales. Ce sont en quelque sorte des lieux destinés avant tout aux touristes.

Les musées régionaux ont habituellement le mandat de travailler aux identités régionales. À cet égard, les ethnologues ont toujours excellé dans ce secteur. Comme on abandonne peu à peu ce type de musée, on voit également disparaître les ethnologues qui avaient développé une perspective identitaire dans ces musées régionaux.

Un nouveau type de musée d'ethnographie : les économusées

La crise économique qui frappe la culture et plus particulièrement le réseau des musées au milieu des années 1990 va permettre l'émergence d'une toute nouvelle forme de muséologie. Le concept des économusées arrive à point nommé. Le contexte est on ne peut plus favorable à ce type d'équipement culturel et économique.

Les économusées ${ }^{17}$ apparaissent comme une alternative aux musées d'ethnographie, tout en offrant une solution moderne au problème du financement des institutions muséales. Mais le plus intéressant, c'est que ce type d'institution favorise la connaissance et la mise en valeur de savoir-faire traditionnels et artisanaux. En ce sens, les économusées s'inspirent profondément de l'approche ethnographique. Faut-il le rappeler, le concept original est l'œuvre de Cyril Simard, un ethnologue qui a longtemps œuvré dans le monde des métiers d'art ainsi qu'au Musée du Québec. On lui doit une des formes les plus originales de la nouvelle muséologie nord-américaine. Ce concept a franchi les frontières du Québec et on retrouve des économusées au NouveauBrunswick, à l'île du Prince-Édouard, en Nouvelle-Écosse et à TerreNeuve.

17. Comme il existe peu d'ouvrages sur ce type de musée, on peut consulter le site internet de la Société internationale des entreprises économusée : www.economusees.com 


\section{1 : le projet du Musée des ATP de Trois-Rivières}

Dans ce bilan des années 1990, on ne saurait passer sous silence le cas du Musée des arts et traditions populaires de Trois-Rivières. Il s'agit probablement de l'échec le plus déplorable qu'on ait pu observer au Québec. Ce projet a eu et a encore aujourd'hui des conséquences importantes sur la muséologie et l'avenir des musées d'ethnographie.

Sans vouloir épiloguer sur les raisons qui expliquent la fermeture du Musée deux ans à peine après son ouverture, on ne peut s'empêcher d'établir quelques constats.

1- Le simple fait de s'être inspiré du musée des arts et traditions populaires de Paris constitue en soi une erreur fondamentale. On doit reconnaître que le concept original du Musée des ATP de Paris est apparu au milieu des années 1970 comme un modèle original et novateur. Cependant, ce Musée a connu des difficultés telles qu'il sera bientôt démantelé pour prendre une autre forme et une nouvelle mission à Marseille.

2- L'équipe initiale du musée de Trois-Rivières a eu du mal à faire de ce musée un musée d'ethnologie. Le discours et la manière ne collaient plus à la réalité.

3- Enfin, le fait de s'inspirer du Musée de la civilisation, sans disposer des mêmes besoins, n'a pas donné de bons résultats. Le musée n’a pas réussi à trouver sa propre identité et à devenir un lieu de convergence dans son milieu.

4- On doit reconnaître que le budget de fonctionnement accordé par le ministère de la culture a contribué à créer au musée un état de crise. En ne donnant pas au Musée de Trois-Rivières le budget nécessaire pour assumer sa mission, le ministère condamnait du même coup ce musée.

5- La conséquence la plus grave de cette aventure, c'est que, dans l'opinion publique comme dans l'opinion des muséologues, il semble que le modèle des musées d'ethnographie soit dépassé. Il s'agit peutêtre du dernier musée auquel on a confié une mission aussi précise au Québec. 


\section{Le Musée de la dernière chance}

La relance du musée des Arts et traditions populaires, qui est devenu le Musée québécois de culture populaire, en est à sa dernière chance. Le 29 septembre 2000, le Comité de relance déposait un rapport de relance à la ministre de la Culture et des Communications. Le Musée doit donc réouvrir ses portes au printemps 2003. Si le public ne suit pas cette fois, il est probable que le musée ne puisse s'en remettre et que le ministère choisisse de le fermer définitivement. Quoiqu'il advienne, on doit retenir que ce n'est pas le fait que ce musée ait été défini comme un musée d'ethnographie qui pose un problème fondamental. Les difficultés résident davantage dans les stratégies de médiation. Le Musée de la civilisation a démontré que le concept et la manière d'échanger avec les publics du musée comptent davantage que les orientations scientifiques. En d'autres termes, c'est la médiation, c'est-à-dire le rapport aux visiteurs, qui détermine le succès d'une institution muséale.

\section{La place de la recherche et des collections}

La place de la recherche dans les musées régionaux se trouve à toute fin pratique élaguée. Malgré ces prises de positions discutables, les musées conservent encore des collections ethnographiques. À cet égard, le Musée de la civilisation a mené entre 1998 et 1991 une vaste enquête dans le réseau des musées québécois de manière à identifier les principales collections ethnographiques (Denis 1993). Comme le souligne Christian Denis, sans être exhaustif, cet inventaire permet dans un premier temps d'identifier 55 musées pouvant conserver des collections ethnographiques. Après analyse, on a retenu 50 musées. La grille d'analyse s'inspire du système de classification de Robert G. Chenhall publié en 1978. À cette classification, on a ajouté deux catégories de manière à identifier les objets amérindiens et les objets liés aux communautés ethniques. Il apparaît assez clairement dans ce rapport qu'il existe d'importantes collections ethnographiques dans le réseau des musées québécois. La lecture des tableaux indique également que les musées disposent d'une documentation sommaire de ces collections. Bien que l'informatisation des collections entreprise au début des années 1990 ait permis de mieux connaître ce patrimoine ethnographique, les bases de données ne nous donnent accès qu'à très peu d'informations. Au mieux, on a identifié les objets, on a précisé le lieu exact d'entreposage et on a noté l'état de conservation. En bref, 
cette opération visait d'abord et avant tout à dénombrer les objets et à permettre la gestion administrative du patrimoine québécois. Au plan de la recherche, on constate que tout reste à faire.

\section{Bilan : crise du savoir et de la formation}

Il apparaît indéniable que le programme d'ethnologie a joué un rôle fondamental dans la formation des premiers muséologues au Québec. Conséquemment, les ethnologues ont influencé, au cours des trente-cinq dernières années, le développement du réseau des musées au Québec en favorisant la mise en valeur des collections ethnographiques et de la culture populaire.

À la lumière de ce retour historique sur les musées d'ethnographie au Québec, on peut parler d'une véritable crise identitaire des musées d'ethnographie qui a commencé à se faire sentir au début des années 1990. Qu'en est-il en 2002 du réseau des musées d'ethnographie? Objectivement, peu de musées se définissent comme des musées d'ethnographie ou d'ethnologie. Cependant, tout comme en 1967, alors que Jean-Claude Dupont découvrait ces petits musées régionaux, on retrouve aujourd'hui d'importantes collections d'objets ethnographiques qui témoignent de la culture populaire québécoise. Trente-cinq ans plus tard, on observe les mêmes problèmes fondamentaux qui refont surface. La connaissance que nous avons de ces collections ethnographiques demeure élémentaire. Dans la majorité des cas, les conservateurs et muséologues qui ont la responsabilité de ces musées ne disposent pas de la formation nécessaire pour étudier et interpréter ces collections. C'est pourquoi il y aurait lieu de faire une place à de jeunes ethnologues dans ces musées, pour travailler à la documentation des collections.

Lorsqu'on examine attentivement la formation offerte en muséologie à l'Université de Montréal, à l'Université du Québec à Montréal ou à l'Université Laval, on est frappé par l'accent mis sur la communication et la médiation des patrimoines. La formation actuelle en muséologie a permis de former d'excellents professionnels qui maîtrisent parfaitement les concepts de communication en muséologie. Ils ont acquis ici et à l'étranger une reconnaissance certaine. Cependant, les programmes de muséologie ne consacrent pas assez de temps à la formation fondamentale en muséologie. On ne doit pas perdre de vue 
que les muséologues travaillent d'abord et avant tout avec des objets et des œuvres. À ce chapitre, on ne forme toujours pas de conservateurs au Québec. Bien sûr, l'histoire de l'art forme des conservateurs pour travailler dans les collections beaux-arts, mais nous ne formons pas de conservateur pour prendre en charge les collections ethno-historiques qui constituent une large part du patrimoine québécois. À ce chapitre, nous faisons face à un déficit majeur. Le Québec forme des muséologues spécialistes de la communication, mais pas de conservateurs disposant des connaissances fondamentales en culture matérielle. Bien que l'expertise québécoise soit reconnue en Europe, les muséologues européens reconnaissent également cette grande faiblesse dans la formation des muséologues québécois. Il ne faut pas perdre de vue que le travail de muséologue concerne pour l'essentiel des objets de culture matérielle. À juste titre, on a longtemps reproché aux muséologues québécois d'être trop centrés sur les collections. Les programmes de formation en muséologie ont répondu aux attentes des musées en formant des muséologues sensibles à la communication. Malheureusement, on a trop négligé le travail fondamental sur les collections. Il y aurait lieu de rétablir l'équilibre entre ces deux grandes fonctions car on risque fort de se retrouver dans quelques années avec des muséologues qui se désintéresseront de la ressource fondamentale des musées. Les objets auront-ils encore leur place dans les musées d'ethnographie ? Voilà la véritable question.

Comme l'avaient imaginé George-Henri Rivière et Jean-Claude Dupont à une autre époque, le musée d'ethnographie doit être un lieu de mémoire, un lieu de connaissance et un lieu de rassemblement pour les collectivités. Aujourd'hui comme en 1967, les musées d'ethnographie continuent trop souvent à n'être que des cabinets de curiosités, précisément parce qu'il n'y a pas d'ethnologues pour analyser et révéler le véritable sens de ces collections. En abandonnant la formation en culture matérielle des muséologues, on a créé une fracture entre la médiation du patrimoine et les savoirs. Ce phénomène que l'on observe au Québec prend des formes différentes en France, mais le problème fondamental reste le même. Les jeunes ethnologues et conséquemment les nouveaux muséologues deviennent de moins en moins sensibles à l'étude des objets.

L'ethnologie, on l'a bien démontré, a contribué de manière fondamentale au développement des musées au Québec. Elle a orienté et inspiré notamment la manière originale du Musée de la civilisation 
comme musée de société qui a joué un rôle de leader au plan national et international. La reconnaissance du Musée de la civilisation a également mis en relief la nécessité pour les muséologues de prendre des distances avec les approches disciplinaires. Dans cette perspective, est-ce que les musées d'ethnographie sont appelés à disparaître ? Je crois fondamentalement que l'approche humaniste de l'ethnologie a toujours sa place. Si la tendance que l'on observe depuis quelques années se maintient, les musées vont continuer à se spécialiser ${ }^{18}$. Cependant, l'approche et le regard que pose l'ethnologie sur la culture populaire demeure toujours actuel et inspirant. Par ailleurs, quoiqu'on en dise et quoiqu'on en pense, les musées, qu'ils se définissent comme des musées de société ou des musées d'histoire, vont continuer à constituer des collections d'objets ethnographiques. Il y aura de l'avenir pour les musées d'ethnographie dans la mesure où l'ethnologie reprendra sa place dans le champ de la culture matérielle et qu'elle permettra une interprétation des objets qui fasse appel au savoir et à l'intelligence, car la véritable crise se situe précisément sur ce terrain.

18. J'ai développé la question des tendances en muséologie en portant une attention toute particulière à la spécialisation des musées que je compare au phénomène de multiplication des médias de communication : radio, télévision, etc. (2002 : 199-210). 


\section{Références}

Arpin, Roland et al., 2000, Un présent du passé. Proposition de politique du patrimoine culturel déposé à Agnès Maltais, ministre de la Culture et des Communications du Québec, Québec, Groupe-conseil sur la politique du patrimoine culturel.

—_, (dir.), 2001, Perspectives et prospectives. Regards sur le Musée 19882001, Québec, Musée de la civilisation.

—_, 1993, Le Musée de la civilisation. Concept et pratique, Québec, Musée de la civilisation / Éditions Multimondes.

—_, 1997, Des musées pour aujourd'hui, Québec, Musée de la civilisation.

—_, 1998, Le Musée de la civilisation: Une histoire d'amour, Québec, Musée de la civilisation / Fides.

- et Yves Bergeron, 2001, «Jean-Claude Dupont: du Musée de l'Homme du Québec au projet d'Institut national de la civilisation », dans Pichette, Jean-Pierre et al., Entre Beauce et Acadie. Facettes d'un parcours ethnologique, Études offertes au professeur Jean-Claude Dupont, Québec, Les Presses de l'Université Laval : 407-421.

Barbeau, Marius, 1937, Québec où survit l'ancienne France, Québec, La Librairie Garneau limitée.

— 1957, Trésor des anciens Jésuites, Ottawa, Musée national du Canada.

Béland, Mario, 1985, dans Porter, John R. (dir.), Marius Barbeau et l'art au Québec: bibliographie analytique et thématique, Québec, CELAT. Bergeron, Yves, 2002, Un patrimoine commun: les musées du Séminaire de Québec et de l'Université Laval, Québec, Musée de la civilisation.

__, 1996, Trésors d'Amérique française, Montréal, Fides.

—. André Allaire et Luc Dupont, 2002, «La médiation au Musée de la civilisation », dans Patrimoine et identités, Québec, Musée de la civilisation - UQAM, Éditions Multi-Monde : 173-213.

Bouchard René (dir.), 1983, La vie quotidienne au Québec. Histoire, métiers, techniques et traditions - Mélanges à la mémoire de RobertLionel Séguin publiés sous les auspices de la Société québécoise des ethnologues, Sillery, Presses de l'Université du Québec.

Couture, Marcel, été 1992, "Des musées pour le troisième millénaire ", Forces $\mathrm{n}^{\circ}$ 98, Plein feux sur les musées / Museums in the spotlight, Québec: 2.

Cuisenier, Jean et Marie-Chantal de Tricornot, 1987, Musée national des arts et traditions populaires. Guide, Paris, Ministère de la Culture 
et des Communications, Éditions de la Réunion des musées nationaux. Denis, Christian, 1993, Un inventaire sommaire des collections ethnographiques des musées québécois, Québec, Musée de la civilisation.

Desdouits, Anne-Marie et Laurier Turgeon (dirs.), 1997, Ethnologies francophones de l'Amérique et d'ailleurs, Québec, Presses de l'Université Laval.

Dubé, Richard, 1998, Trésors de société, Québec, Musée de la civilisation.

Du Berger, Jean, 1997, «Folklore et ethnologie à l'Université Laval », dans Anne-Marie Desdouits et Laurier Turgeon (dirs.), Ethnologies francophones de l'Amérique et d'ailleurs, Québec, Presses de l'Université Laval : 5-24.

Dumouchel, Gilles, Francine Paradis et Yves Bergeron, 1987, La Loi sur les biens culturels et son application, Québec, ministère des Affaires culturelles.

Dupont, Jean-Claude, 1979, L'artisan forgeron, Québec, Éditeur officiel/ Presses de l'Université Laval.

__ 13 novembre 1967, Projet visant à remplacer le Musée de l'homme du Québec par L'Institut national de la civilisation du Québec et les Galeries de la civilisation du Québec, Service du Musée de l'homme du Québec.

__ 1997, "L'étude de la culture matérielle », dans Anne-Marie Desdouits et Laurier Turgeon (dirs.), Ethnologies francophones de l'Amérique et d'ailleurs, Québec, Presses de l'Université Laval : 25 48.

Grandmont, Gérald, 1991, "Longue gestation d'un jeune musée », Cap-aux-Diamants $\mathrm{n}^{\circ} 25$, printemps : 56-59.

— territoire ", Forces n ${ }^{\circ}$ 98, Plein feux sur les musées / Museums in the spotlight, Québec : 4-10.

Garneau, Marthe, 1979, Bibliographie de l'oeuvre de Monsieur Gérard Morisset, membre de la Société royale du Canada, 1950-1962, Montréal, Bibliothèque nationale du Québec.

Lallier, Jean-Paul, mai 1976, Pour l'évolution de la politique culturelle. Document de travail, Québec, ministère des Affaires culturelles.

La muséologie selon Georges Henri Rivière, Cours de muséologie / Textes et témoignages, 1989, Paris, Dunod.

Les chemins de la mémoire. Monuments et sites historiques du Québec, 1990 1999, tome 1, Québec, Éditeur officiel. 
Lessard, Michel, 1971, Encyclopédie des antiquités du Québec. Trois siècles de production artisanale, Montréal, Éditions de l'Homme.

-__-, 1972, Encyclopédie de la maison québécoise. Trois siècles d'habitations, Montréal, Éditions de l'Homme.

__, 1994, Objets anciens du Québec. La vie domestique, Montréal, Éditions de l'Homme.

—_, 1995, Antiquités du Québec, Montréal, Éditions de l'Homme.

__ 1999, Meubles anciens du Québec, Montréal, Éditions de l'Homme.

Le trésor de la langue française, http://atilf.inalf.fr/tlfv3.htm

Martin, Paul-Louis, 1983, «L'ethnographie au Québec. Bilan critique d'une période, 1970-1980 », dans Question de culture 5, Québec, IQRC : 149-182.

Le macro-inventaire du patrimoine québécois, 1985, Québec, les publications du Québec.

Ministère des Affaires culturelles du Québec, 1981, À la découverte du patrimoine avec Gérard Morisset : exposition présentée au Musée du Québec du 4 février au 1 1er mars 1981, Québec.

— vivante $\mathrm{n}^{\circ} 14$, Québec.

Ministère de la Culture et des Communications, 2000, Vivre autrement la ligne du temps: Politique muséale, Québec.

Ministère de la main d'œuvre et de la sécurité du revenu, 1987, Devis de formation professionnelle : conservateur de musée, Québec, Direction du développement de programmes.

Montpetit, Raymond, 2002, «Musées et muséologie. Un champ de recherche dynamique en émergence », dans Lemieux, Denise (dir.), Traité de la culture, Québec, IQRC et Presses de l'Université Laval : 81-94.

Moussette, Marcel, 1983, Le chauffage domestique au Canada (des origines à l'industrialisation), Québec, les Presses de l'Université Laval, coll. Ethnologie de l'Amérique française.

_ 1982 , «Sens et contresens de l'étude de la culture matérielle au Québec ", dans Des objets et des hommes / People and Things, Canadian Folklore canadien vol. 4, $\mathrm{n}^{\text {os }}$ 1-2: 7-42.

Pichette, Jean-Pierre et al., 2001, Entre Beauce et Acadie. Facettes d'un parcours ethnologique, Études offertes au professeur Jean-Claude Dupont, Québec, Les Presses de l’Université Laval, 2001. 
Séguin, Robert-Lionel, 1967, La civilisation traditionnelle de l' «habitant » aux $17^{e}$ et $18^{e}$ siècles, Montréal, Fides.

Simard, Cyril, Andrée Lapointe et Corneliu Kirjan, 1992, Patrimoine muséologique au Québec. Repères chronologiques, Québec, Commission des biens culturels du Québec.

Société internationale des entreprises économusée : www.economusees.com

Vaugeois, Denis, 1979a, Le Musée du Québec en devenir. Concept muséologique, Québec, ministère des Affaires culturelles.

__ 1979b, Le musée du Québec et son avenir. Programme muséologique, Québec, ministère des Affaires culturelles.

Vodden, Christy, 1992, Pierre par pierre. Les 150 premières années de la Commission géologique du Canada, Ottawa, Énergie, mines et ressources Canada. 